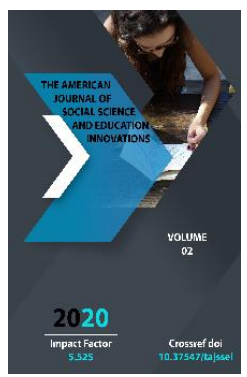

\title{
Modern Methods Of Sociological Research Of Ecological Problems
}

\author{
Eshmurodov Nabillo Ibodullo Ugli
}

Student Of Magistracy Of The North Caucasus Federal University, Uzbekistan

Copyright: Original content from this work may be used under the terms of the creative commons attributes 4.0 licence.

\section{ABSTRACT}

The article examines the foundations of social ecology, as well as the methods that are used in the study of environmental problems.

\section{KEYWORDS}

Methods of sociological research, environmental problems, environmental sociology.

\section{INTRODUCTION}

For the social sciences, environmental problems are inextricably linked with the problem of man, his culture, history, consciousness. The term "ecology" does not sufficiently characterize the peculiarities of the relationship between man and nature, the place of man in the biosphere. All this became the reason for the selection of a special area of research - social ecology. This, in the opinion of many researchers, was initiated by the book by R. Carson, "Silent Spring", published in 1961. It began the stage of accumulating data on the negative environmental consequences of scientific and technological progress, which showed that there is an environmental crisis on the planet. 
In modern sociology, environmental problems are studied quite actively. Some areas of ecological sociology are the most developed: for example, many works are devoted to the consideration of urban ecology, the impact of urbanization processes on the state of ecology in the world (O.N. Yanitsky), the typology of the main environmental problems and their factors (N.N. Moiseev), the history of the creation of ecological consciousness (A. Zelenkov), the balance of social and natural influences, etc.

Ecosociology (ecological sociology) is a direction that studies the relationship of various social groups and classes to the natural environment and the structure of their relationships, determined by their relationship to the natural environment. This direction is closer to the humanities than to natural science.

Ecosociology is still a new branch of science, in connection with which the allocation of its subject remains rather problematic and allows for a fairly broad definition. At the same time, this line of research includes a number of concepts that have a fairly definite interpretation. These include the concept of the environment and its quality. The category "environmental quality" is actively developing at the intersection of the theory of the quality of life and ecosociology.

The concept of the environment is well known. It refers to the entire system of elements of natural and anthropogenic origin that have a direct and indirect impact on humans. Previously, the environment was understood only as natural factors, then factors of natural and anthropogenic origin, but only physical. At this stage, this concept also includes psychological and social factors.

\section{MATERIALS AND METHODS}

Environmental elements are conventionally divided into two main groups: natural and social. All elements related to the geographic location, climate and other physical characteristics of the region are natural. All natural phenomena significantly affect human well-being, his satisfaction with life in general. Therefore, all of the above are factors in the quality of life of the population.

The social elements of the environment include manifestations of the social that affect living conditions and health: housing conditions, microenvironment, economic, ideological, political living conditions of the population. Recent studies convincingly prove that social factors are no less significant, and sometimes even more destructive for human health than natural ones. A striking example is the consequences of the "transition" period experienced by Russian society, when precisely economic, political and ideological reasons led to a sharp increase in mortality and morbidity.

\section{RESULT AND DISCUSSION}

The variety of risks and the corresponding indicators can be measured based on the opinions of experts and the general public, with an emphasis on one or another option, depending on the specifics of the indicator. Most of the experts' opinions are researched through in-depth interviews. Based on the results of a qualitative study, it is possible to draw up a map of the environmental risks of a territory, as well as the possible consequences of problem situations. It is not possible to interview a large sample of the population with in-depth interviews, therefore, a survey using a questionnaire is the most relevant. Such a study will identify problematic situations and risks that, if escalated, can turn into protest 
movements. Also, on the basis of statistical information, it is possible not only to predict environmental sentiments, but also to draw up the necessary recommendations.

Due to the particular complexity of understanding the perception of risk by different actors, a complex methodology is required that covers a large number of phenomena and processes. In this case, the following indicators serve as the basis for building the toolkit: the attractiveness of the city for living, the safety of the urban environment, the level of development of the ecological culture of the townspeople, the ecological place in the system of perception of risk factors, the assessment of the general ecological state and the level of pollution, the assessment of the health status of the population, the assessment of the level of environmental responsibility of production, the assessment of public participation in solving the environmental problems of the city , assessment of the city's environmental policy.

\section{CONCLUSION}

The risks associated with the environment are perceived by the population with varying degrees of severity and depend on the nature of the area and the socio-cultural interpretation of the risk. According to selfassessment, among the factors determined by the environment, the general state of the environment and the problems caused by transport have the greatest impact on the population, i.e. traffic jams and their consequences in the form of gas pollution. On the basis of mass polls, one can judge the ecological well-being of the population, which will allow identifying the most problematic situations of an ecological nature, as well as the implementation of the social consequences of such problems.

A comparative analysis can lead to the conclusion that experts and the public agree on most issues, or at least do not contradict each other. However, for a more relevant assessment, it is first necessary to conduct a quantitative survey of the population. You can use it to determine not only the main criteria affecting residents, but also the level of tension, which allows you to more accurately predict social and environmental well-being and human behavior.

\section{REFERENCES}

1. Beck W. Risk Society. On the way to another modern / $M$.: Progress-Tradition, 2000. - 383 p.

2. Gorelov A.A. Social ecology / A.A. Gorelov. M .: Moscow Lyceum, 2002.

3. Kipriyanova M. A. On the place of social ecology in sociology [Electronic resource] // URL: https://cyberleninka.ru/article/n/omeste-sotsialnoy-ekologiii-v-sotsiologii 